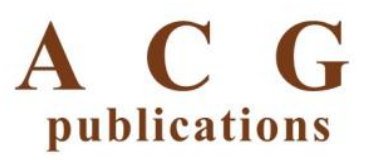

Org. Commun. 10:3 (2017) 135-143

organic

communications

\title{
GAP pre-polymer, as an energetic binder and high performance additive for propellants and explosives: A review
}

\author{
Mehmet S. Eroglu ${ }^{\oplus 1,2^{*}}$ and Muge S. Bostan ${ }^{\oplus 1}$ \\ ${ }^{1}$ Department of Chemical Engineering, Marmara University, Istanbul, Türkiye \\ ${ }^{2}$ TUBITAK-UME, Chemistry Group Laboratories, Kocaeli, Türkiye
}

(Received July 22, 2017; Revised August 21, 2017; Accepted August 22, 2017)

\begin{abstract}
In preparation of energetic composite formulations, functionally terminated pre-polymers have been used as binder. After physically mixing the pre-polymers with oxidizing components, metallic fuel, burning rate modifier and other minor ingredients, they are cured with a suitable curing agent to provide physical and chemical stability. These pre-polymers could be functionalized with carboxyl, epoxide or hydroxyl groups at varying average chain functionalities. For carboxyl-terminated pre-polymers, an epoxy functional curing agents could be used. If the prepolymer possesses hydroxyl groups, isocyanate functional curing agents are the most suitable curing agents in terms of easy and efficient processing. Glycidyl azide polymer (GAP) is one of the well-known low-molecular weight energetic liquid pre-polymer, which was developed to use as energetic binder, high performance additive and gas generator for high performance smokeless composite propellant and explosive formulations. Linear or branched GAP can be synthesized by nucleophilic substitution reaction of corresponding poly(epichlorohydrin) (PECH) with sodium azide through replacement of chloromethyl groups of $\mathrm{PECH}$ with pendant energetic azido-methyl groups on the polyether main chain. Positive heat of formation $(+957 \mathrm{~kJ} / \mathrm{kg})$ enables exothermic and rapid decomposition of GAP producing fuel rich gases. Its polyether main chain provides GAP with relatively low glass transition temperature $\left(\mathrm{Tg}=-48^{\circ} \mathrm{C}\right)$ and presence of hydroxyl functional groups allows it to have easy processing in curing with isocyanate curing agents to form covalently crosslinked polyurethane structure. These outstanding properties of GAP enable it to be used as energetic polymeric binder and high performance additive in preparation of energetic materials and low vulnerable explosives.
\end{abstract}

Keywords: GAP; glycidyl azide polymer; PGA; polyglycidyl azide; energetic materials. C2017 ACG Publications. All rights reserved.

\section{Introduction}

GAP was first achieved by Vandenburg ${ }^{1}$ in 1972 by the reaction of sodium azide with PECH-triol in dimethyl formamide. Frenkel and co-workers synthesized PECH-triol, through a cationic ring opening polymerization of epichlorhydrin using glycerol as an initiator, which was further used for the synthesis of branched GAP. PECH-diol was later synthesized using ethylene

\footnotetext{
* Corresponding author: E-Mail: mehmet.eroglu@marmara.edu.tr, Phone: + 90 (216) 3480292 ext. 1720 
glycol as an initiator and it was converted to liner $\mathrm{GAP}^{2-4}$. Ampleman reported a method for the preparation of linear GAP having increasing hydroxyl functionality ${ }^{5}$.

\section{Synthesis of GAP}

The synthesis of GAP is more specific than other energetic materials since, unlike other energetic materials, GAP is obtained by a small modification of its precursor polymer, PECH. Thus, it is obtained by the azidation of $\mathrm{PECH}$ having number average molecular weight $(\bar{M} n)$ between $500-5000 \mathrm{~g} / \mathrm{mol}$ which is synthesized by cationic ring opening polymerization of epichlorohydrin $(\mathrm{ECH})$ in the presence of Lewis acids as a catalyst ${ }^{1,2,6}$. The azidation reaction is performed in an amphiphilic organic solvents such as dimethyl acetamide, dimethyl formamide etc., at $100{ }^{\circ} \mathrm{C}$ in the presence of quaternary ammonium salts as phase transfer catalyst (Figure 1)

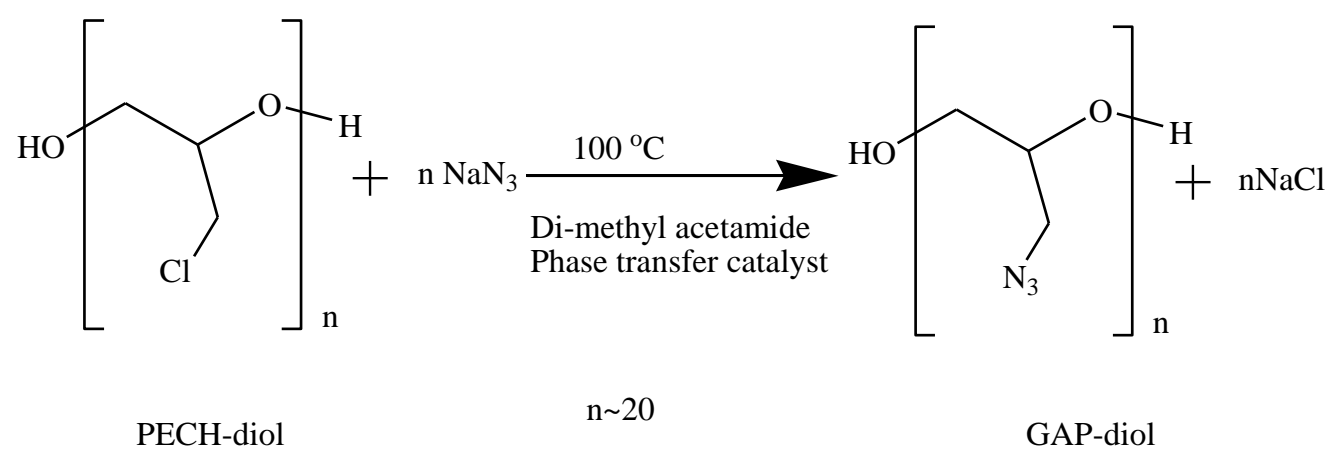

Figure 1. Synthesis of GAP-diol

Synthesis of GAP is followed by spectroscopic and thermal analysis techniques. Kubota and Sonobe ${ }^{7}$ showed that the thermal decomposition of GAP has two weight-loss steps. The first weight-loss step is due to the exothermic decomposition of azide groups resulting in acrylonitrilelike structure. The second weight-loss step corresponds to degradation of the remaining polyether main chain. Considering the characteristic two step degradation behavior of GAP, Eroglu et al. real-time followed the conversion of azidation reaction using thermal gravimetric analysis (TGA) and differential scanning calorimetry (DSC) as well as Fourrier transform infrared (FTIR) and UV-VIS spectroscopy techniques. Conversion of the reaction was ascertained from changes in characteristic IR peak intensities and thermal behavior of reaction products as a function of time which was found to be a first order reaction with a rate constant of $k=0.74 \mathrm{~h}^{-1} 8$.

Mohan et al. synthesized GAP polymers with different diol structures via azidation of the corresponding precurser, PECH. The stability and glass-transition temperature were found to be dependent on the diol unit present on the polymer chains ${ }^{9}$. As a new energetic plasticizer, acyl terminated GAP was synthesized through the reaction of 2,4,6-trinitrobenzoyl (TNB) chloride with GAP. Detailed chacterization studies were performed ${ }^{10}$. To obtain a more safe energetic material with better mechanical properties methyl glycidyl azide polymer was synthesized and detailed characterization was performed ${ }^{11,12}$.

The nature of the terminal hydroxyl groups of GAP influences its mechanical properties. In the cours of curing with isocyantes. As the primary hydroxy groups are more ractive than secondary hydroxy groups primary hydroxyl terminated GAP was synthesized to improve the mechanical properties ${ }^{13}$. Kshirsagar et al. performed a microwave assisted synthesis of GAP with different diol units, for which the PECH precursers containing different diol units were reacted 
with sodium azide under microwave irradiation $(600 \mathrm{~W})$ at $80{ }^{\circ} \mathrm{C}$ for $12 \mathrm{~min}$. The detailed thermal and spectroscopic characterization was performed ${ }^{14}$. In addition to GAP, aiming to develope less sensetive and highly energetic propellant formulations, various energetic azido polymers such as 3,3,bis(azidomethy1)oxetane polymer (BAMO), 3-azidomethyl 3-methyl oxetane polymer (AMMO) and their copolymers have been synthesized ${ }^{15-20}$.

\section{Copolymers and Other Derivatives of GAP}

Although GAP-diol is a well known energetic pre-polymer, it has insufficient mechanical properties for composite propellant formulations relative to butadiene-based (PBD) pre-polymers. Therefore, its various copolymers were synthesized to improve the physical and chemical properties to expand its application area. Min, recently cured the GAP-diol with di-isocyanate and pluriisocyanate (containing more than two isocyanate groups) in the presence of poly(ethylene glycol), PEG, poly(caprolacton)-diol and PCL-diol. Incorporation capability of various energetic plasticizers into the networks was investigated ${ }^{21}$. Ampleman synthesized a di-azido terminated glycidyl azide polymer as an energetic plasticizer. ${ }^{22}$

Pisharath et al. ${ }^{23}$ synthesized a copolymer of GAP-diol and an another energetic azide polymer, poly(bis(azidomethyl)oxetane), Poly(BAMO), using borontrifluoride dimethyl ether complex/diol initiator system to study thermal decompositon behavior of the copolymer. DSC studies of the copolymer showed a main decomposition step arising from the azide groups as a broad exothermic peak at higher temperature than that of GAP-diol $\left(298{ }^{\circ} \mathrm{C}\right)$. Subramanian ${ }^{24}$ synthesized GAP-PBD-GAP energetic triblock copolymer by means of azidation of poly(chloromethyl ethylene oxide-b-butadiene-b-chloromethyl ethylene oxide) (PECH-PBDPECH) using sodium azide in dimethyl acetamide-toluene mixture at $95{ }^{\circ} \mathrm{C}$. In this study, the spectroscopic, thermal and chromatographic characterization studies of the copolymer were performed. Using this copolymer, Ammonium perchloride (AP) based polyurethane propellant formulation was prepared and their ballistic parmeters were determined. As an another interesting method for the block copolmerization of GAP-diol with a vinyl monomer was oxidation of functional $-\mathrm{CH}_{2}-\mathrm{OH}$ groups of GAP-diol with transition metal ions. In this method, cerium (IV) was used as versatile oxidation ragent to produce radical sites on both ends of GAP-diol according to mechanism given in Figure $2 .{ }^{25}$. The succesful synthesis and characterization of GAP-PMMAGAP type block copolymer by redox polymerization was reported. 


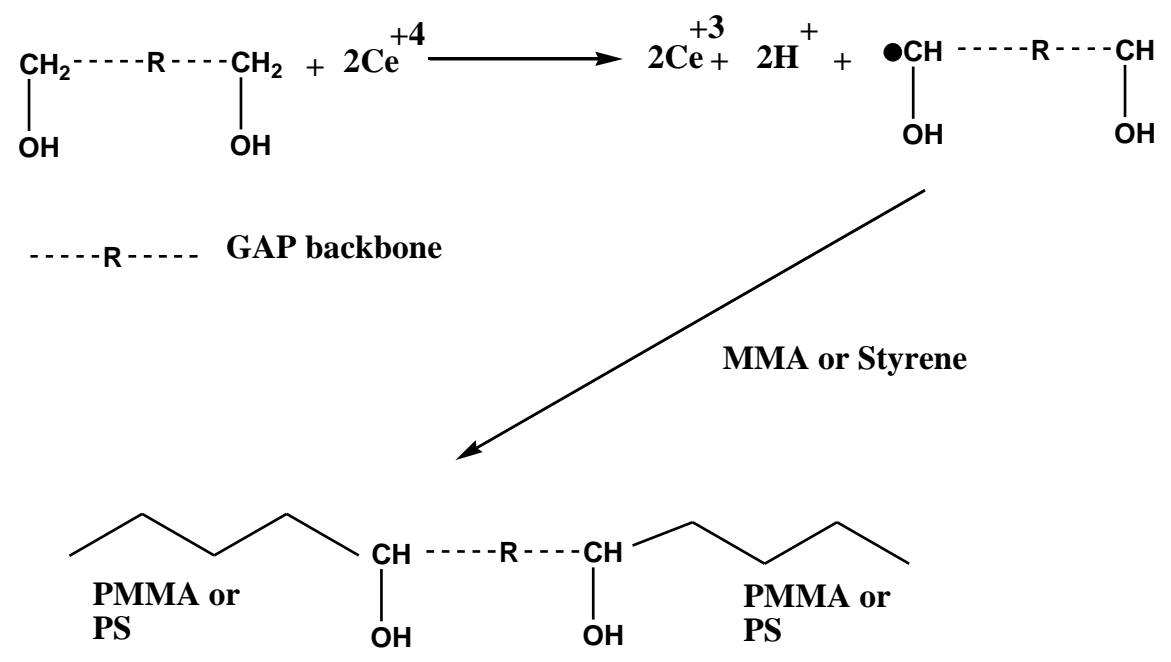

Figure 2. Synthesis of GAP-PMMA-GAP block copolymer initiated using Ce(IV) as initiator

Macro-azo-initiators provide a useful and versatile method for the synthesis of different block copolymers via radical process. Macroazo-initiators can be prepared by the condensation reaction of a prepolymer with azobis-isobutyronitrile,4',4' azobis(4-cyanopentanoyl chloride) and 4',4' azobiscyanopentanol. Eroglu et al. synthesized block copolymers of GAP-diol and its precurser $\mathrm{PECH}-$ diol with styrene and methylmethacrylate according to the mechanism given in Figure $3{ }^{26}$ 


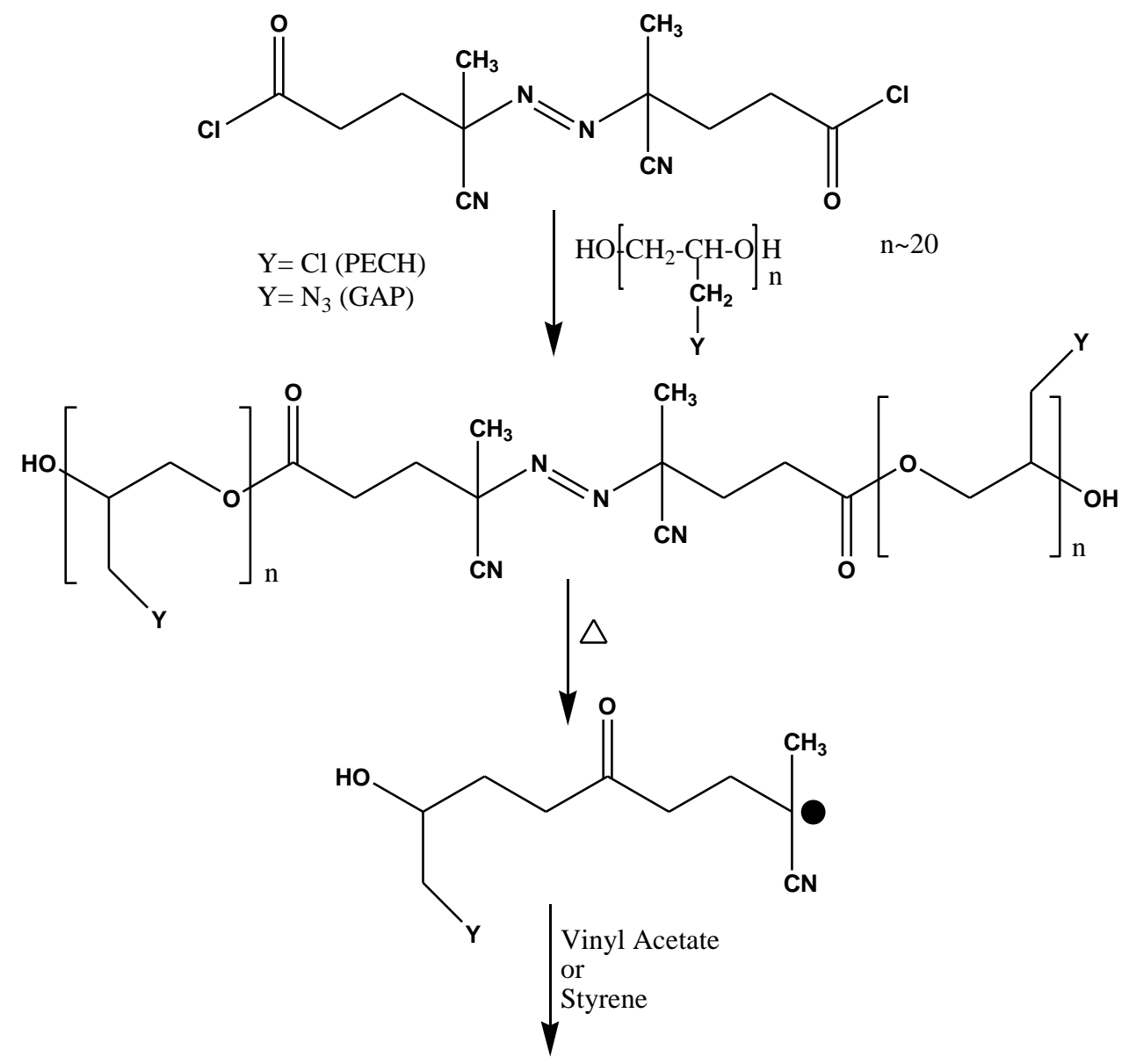

PECH-b-PS, PECH-b-VAc GAP-b-PS, GAP-b-VAc block copolymers

re 3. Synthesis of the block copolymers of GAP-diol and its precurser PECH-diol with styrene and vinyl

Zhang et al. synthesized chloroethyl methacrylate terminated PECH based macroinitiators to use in the synthesis of GAP-b-poly(azidoethyl methacrylate), GAP-b-PAEMA, copolymer ${ }^{27}$. Regarding the unique thermal properties of GAP-diol and physico-chemical properties of HTPB at relatively low temperatures, a HTPB-g-PGA copoymer was prepred and characterized. As this graft copolymer was expected to have promising polymeric binder in solid propellants, macroazoinitiatior of GAP-diol was synthesized and attacked to pendant vinyl groups of HTPB via radical mechanism at $90{ }^{\circ} \mathrm{C}$. DSC results showed the presence of two incompatible block segments on the copolymer structure resulting in immiscibility ${ }^{28}$. Al-Kaabi et al. synthesized GAP carrying pendant $\mathrm{N}, \mathrm{N}$-diethyl dithiocarbamate groups and used as macro-photoinitiator for grafting of methylmethacrylate onto the polyether main chain. ${ }^{29}$

Submarian reported the synthesis and characterization of an energetic triblock copolymer, hydroxyl-terminated poly (azidomethyl ethylene oxide-b-butadiene-b-azidomethyl ethylene oxide) (GAP-PBD-GAP). A detiled structural characterization was performed. its potential as a binder for ammonium perchlorate based polyurethane propellant formulation was evaluated ${ }^{24}$. 
Jin et al. synthesized a series of poly(vinyl 2,4,6-trinitrophenylacetal)-g-polyglycidylazides, PVTNP-g-GAP, copolymers at different molecular weight. Two different glass transition temperature and excellent thermal decomposition resistance upto $200{ }^{\circ} \mathrm{C}$ were observed. Sensivity and compability tests showed that these copoylmers could be used in TNT-based melt-cast explosive formulation ${ }^{30}$.

Using GAP and nitrocellulose fibers a double base propellent having a homogeneous structure was synthesized to replace nitroglycerin in double base propellant formulation. Rise of onset decomposition temperature up to $194.6{ }^{\circ} \mathrm{C}$ indicated a good thermal stability, safe storage and operation. $\mathrm{NO}, \mathrm{NO}_{2}, \mathrm{CO}, \mathrm{CO}_{2}, \mathrm{NH}_{3}, \mathrm{CH}_{4}, \mathrm{HCN}, \mathrm{N}_{2}, \mathrm{CH}_{2} \mathrm{O}$ and $\mathrm{C}_{2} \mathrm{H}_{4} \mathrm{O}$ are the main gas decomposition products. ${ }^{31}$.

Triazole type crosslinked GAP networks were prepared as an alternative to polyurethane networks which have been studied by different authors ${ }^{\mathbf{3 1 - 3 5}}$ Click chemistry with bispropagyl succinate (BPS) via a 1,3-dipolar cycloaddition instead of isocyanates was performed and 1,2,3triazole network was obtained by Reshmi et al. Characterization studies showed that the crosslink density and thus, tensile strength and modulus of elasticity could be controlled by the azide/propargyl ratio. ${ }^{36}$. Another triazole curing system was used for GAP by Ding et al., which was prepared by blending propargyl-terminated polybutadiene (PTPB) with GAPs in the presence of cuprous chloride as catalysis. Various crosslinked systems were prepared at different azide/propargyl group ratios. Triazole crosslinked network resulted in a slight increase in glass transition and $\alpha$-transition temperatures, reflecting the hindered rotation of polymer chain, with increasing miscibility of GAP and PTBT ${ }^{37}$.

Dubois et al. investigated the reaction between azide groups bearing polymers and double, triple bonds of the light olefins which yielded triazole and aziridine cycles. They observed a higher burning rate at relatively lower pressure for triazole substituted GAPs. They described a safe production route with lower molecular weight GAP plasticizer and suggested the use of propargyl alcohol and a semibatch reactor to avoid sudden temperature raise in the reaction mixture ${ }^{38}$.

\section{Decomposition of GAP}

Numerous studies have been performed to ascertain the thermal decomposition behavior of GAP using diferent methods since GAP decomposes very rapidly even at relatively low temperatures. It was observed from DSC and TGA measurments that GAP has two weight loss steps. The first weight loss step is exothermic process accompanying with the elimination of $\mathrm{N}_{2}$ from the azide groups. The energy liberated at this stage was determined to be $1828 \mathrm{~J} / \mathrm{g}$ by DSC ${ }^{7}$, 39 and the activation energy of decomposition was determined as $\mathrm{Ea}=176.4 \mathrm{~kJ} / \mathrm{mol}$. The second weight loss step is due to the decomposition of remaining polyether structure. ${ }^{8,40-42}$.

Eroglu and Guven followed the azide group elimination by taking real time FTIR spectra of GAP at which the sample cell was heated from room temperature to $220{ }^{\circ} \mathrm{C}$ in a controllable manner. During decomposition, while the intensity of the azide absorption peak at $2100 \mathrm{~cm}^{-1}$ started to decrease at $170{ }^{\circ} \mathrm{C}$, new peaks were appeared. They proposed the formation of $-\mathrm{C}=\mathrm{N}-$ $\mathrm{C}$ - type structure as a result of thermal decomposition and, thus, possible croslinked structure ${ }^{39}$. The combustion and thermal decomposition characteristic and their kinetic parameters for cured and liear GAP were studied. The decompositon products of GAP were analysed by molcular beam mass-spectrometry (MBMS) ${ }^{43}$

Kumar and Lee ${ }^{44}$, Has et al. ${ }^{40}$, Tang et al. ${ }^{45}$, studied the photodecompositon of GAP using laser irradiation. $\mathrm{CO}, \mathrm{C}_{2} \mathrm{H}_{2}$ and $\mathrm{HCN}$ were major decomposition products, while minor products were $\mathrm{C}_{2} \mathrm{H}_{4}, \mathrm{CH}_{4}, \mathrm{NH}_{3}$ and $\mathrm{CO}_{2}$.

In another study thermal analysis of branched GAP was investigated using DSC, TGA and acceleating rate calorimetry (ARC) at various heating rates and isothermal conditions. Results 
showed that decomposition activation energy of branched GAP was lower then GAP-tiol indicating less stability of branched GAP then linear GAP ${ }^{46}$

\section{Some Physico-chemical Properties and Network Characterization Studies}

For a composite propellants, mechanical properties and solid loading capacity are two important properties. These properties are inversely proportional such that increasing the solid content results in weakening in mechanical properties while becoming more energetic. Mechanical properties, such as strength and elongation at break values are strongly influenced by number average molecular weight between cross-links $(\bar{M} c)$ of a network. Low $\bar{M} c$ of a network results in high tensile stress and low elongation. Therefore, desired $\bar{M} c$, tensile stress and elongation values can be optimized by reactive group ratios ${ }^{2,6}$. Eroglu and Guven calculated the $\bar{M} c$ values of the GAP networks from their equilibrium swelling values in tetrahydrofuran (THF) at $45{ }^{\circ} \mathrm{C}$. The networks were prepared using different cross-linker systems at different cross-link densities. They reported important thermodynamic parameters of GAP which is polymer-solvent interaction parameter $\left(\chi_{1}\right)$ as 0.25 in $\mathrm{THF}$ at $45{ }^{\circ} \mathrm{C}{ }^{47}$. In another study, Eroglu et al. determined the Hildebrandt solubility parameters of GAP and PECH as $11.0\left(\mathrm{cal}_{\mathrm{cm}} \mathrm{cm}^{-3}\right)^{1 / 2}$ and $11.2\left(\mathrm{cal}_{\mathrm{cm}} \mathrm{cm}^{-3}\right)^{1 / 2}$, respectively ${ }^{48}$.

Mechanical and adhesive properties of propellants are directly related to interface interactions between binder and oxidizers. Therefore, the surface free energy of GAP networks and its change with type of cross-linker and cross-link density are of important. Doğan et al. determined the surface free energy of different GAP networks ${ }^{49}$. Since GAP is an energetic material and starts decomposition at relatively low temperature $\left(\sim 170{ }^{\circ} \mathrm{C}\right){ }^{39}$, the shelf time prediction of GAP and PECH at different temperatures is of great importance. Therefore, the thermo-analytical life time testing of PECH and GAP were performed. As a result of TGA studies, it was understood that if GAP is stored at room temperature, there will be no significant change in its ballistic and viscosity properties 50

\section{Conclusion}

During the last two decades, due to increasing awareness and sensitivity on environmental problems, an increasing effort was performed to develop chlorine free, having high specific impulse and high burning rate and smokeless composites and double base propellant formulations. In formulations, nitro explosives and their derivatives have met these requirements in some extent but they are not as safe as they should be in handling and use. For an energetic material, a high degree of safety in handling and reduced sensitivity to detonation are primarily desired. Considering these requirements, various energetic polymers having azidmethyl groups were developed. GAP is a typical example to them. The hydroxyl terminated polyether main chain structure, having relatively low glass transition temperature $\left(\mathrm{Tg}=-48{ }^{\circ} \mathrm{C}\right)$, low viscosity and relatively high density compared to other polymeric binders attracted the interest of scientists working in the related fields. A number of studies have focused on the synthesis and characterization of GAP and its derivatives, which have been found a wide area of use in explosive formulations. Depending our experience and the literature survey, it could be interesting and useful to release such a short review article for scientists working on this subject.

\section{ORCID}

Mehmet S. Eroglu : 0000-0003-0742-61622

Müge S. Bostan: 0000-0002-2909-689X 


\section{References}

[1] Vandenburg, E. J. Polyethers containing azidomethyl side chains. U.S. Pat. 3,645,917 (1972)

[2] Frankel, M. B.; Flanagan, J. E. Energetic hydroxy-terminated azido polymer. U.S.Pat. 4,268,450 (1981).

[3] Frankel, M. B.; Witucki, E. F.; Dean, O. W. I. Aqueous process for the quantitative conversion of polyepichlorohydrin to glycidyl azide polymer. U.S. Pat. 4,379,894 (1983).

[4] Frankel, M.; Grant, L.; Flanagan, J. Historical development of glycidyl azide polymer. J. Propul. Power. 1992, 8, 560-563.

[5] Ampleman, G. Glycidyl azide polymer. U.S. Pat. 5,359,012 (1994).

[6] Earl, R. A. Use of polymeric ethylene oxides in the preparation of glycidyl azide polymer. U.S. Pat. 4,486,351 A(1984.

[7] Kubota, N.; Sonobe, T. Combustion mechanism of azide polymer. Propell. Explos. Pyrotech. 1988, 13, 172177.

[8] Eroglu, M. S.; Guven, O. Spectroscopic and thermal characterization of poly (glycidyl azide) converted from polyepichlorohydrin. J. Appl. Polym. Sci. 1996, 60, 1361-1367.

[9] Murali Mohan, Y.; Padmanabha Raju, M.; Mohana Raju, K. Synthesis, spectral and DSC analysis of glycidyl azide polymers containing different initiating diol units. J. Appl. Polym. Sci. 2004, 93, 2157-2163.

[10] Huang, T.; Jin, B.; Peng, R.-F.; Chu, S.-J. Synthesis and characterization of a new energetic plasticizer: Acylterminated GAP. Int. J. Polym. Anal. Ch. 2014, 19, 522-531.

[11] Ribeiro, S. P.; Santiago, D. G.; Vianna Jr, A. d. S. Glycidyl azide polymer (GAP). I: syntheses and characterization. Polímeros, 2012, 22, 407-413.

[12] Sciamareli, J.; Costa, J. R. d.; Takahashi, M. F.; Diniz, M. F.; Lourenço, V. L.; David, L. H.; Iha, K.; Miyano, M. H.; Ferreira, C. Characterization of energetic methyl glycidyl azide polymer. Polímeros, 2009, 19, 117-120.

[13] Xiaodong, S. Z. Z. J. Y. R. L. In Synthesis and Characteristic on Primary-hydroxyl Terminated GAP, 9th International Autumn Seminar on Propellants, Explosives and Pyrotechnics, Nanjing, Peoples R China, 2011; Li, S. N., P, Ed. pp 129-132.

[14] Kshirsagar, A.; Gite, V.; Hundiwale, D.; Mahulikar, P. Microwave assisted synthesis and characterization of glycidyl azide polymers containing different initiating diol units. Cent. Eur. J. Energ. Mater. 2015, 12,757767.

[15] Zhang, C.; Li, J.; Luo, Y. Synthesis and characterization of 3, 3'-bisazidomethyl oxetane-3-azidomethyl-3'methyl oxetane alternative block energetic thermoplastic elastomer. Propell. Explos. Pyrotech. 2012, 37 , 235-240.

[16] Talukder, M. A.; Lindsay, G. A. Synthesis and the preliminary analysis of block copolymers of 3, 3'bis (azidomethyl)-oxetane and 3-nitratomethyl-3'-methyloxetane. J. Polym. Sci. A Polym. Chem. 1990, 28, $2393-$ 2401.

[17] Xu, B.; Lillya, C. P.; Chien, J. C. Spiro (benzoxasilole) catalyzed polymerization of oxetane derivatives. $J$. Polym. Sci. A Polym. Chem. 1992, 30, 1899-1909.

[18] Kimura, E.; Oyumi, Y.; Kawasaki, H.; Maeda, Y.; Anan, T. Characterization of BAMO/NMMO copolymers. Propell. Explos. Pyrotech. 1994, 19, 270-275.

[19] Bazaki, H.; Kubota, N. Energetics of AMMO. Propell. Explos. Pyrot. 1991, 16, 68-72.

[20] Oyumi, Y.; Mitarai, Y.; Bazaki, H. Thermal decomposition of AMMO/AP composite propellants. Propell. Explos. Pyrotech. 1993, 18, 168-172.

[21] Sun Min, B. Characterization of the plasticized GAP/PEG and GAP/PCL block copolyurethane binder matrices and its propellants. Propell. Explos. Pyrotech .2008, 33, 131-138.

[22] Ampleman, G. Synthesis of a diazido terminated energetic plasticizer. U.S.Pat. 5,124,463 (1992).

[23] Pisharath, S.; Ang, H. G. Synthesis and thermal decomposition of GAP-Poly (BAMO) copolymer. Polym. Degrad. Stab. 2007, 92, 1365-1377.

[24] Subramanian, K. Hydroxyl-terminated poly (azidomethyl ethylene oxide-b-butadiene-b-azidomethyl ethylene oxide)—synthesis, characterization and its potential as a propellant binder. Eur. Polym. J. 1999, 35, 14031411.

[25] Arslan, H.; Eroglu, M. S.; Hazer, B. Ceric ion initiation of methyl methacrylate from poly (glycidyl azide)diol. Eur. Polym. J. 2001, 37, 581-585.

[26] Eroglu, M. S.; Hazer, B.; Guven, O.; Baysal, B. Preparation and thermal characterization of block copolymers by macroazonitriles having glycidyl azide and epichlorohydrin moieties. J. Appl. Polym. Sci. 1996, 60, 2141-2147.

[27] Zhang, Y.; Zhao, J.; Yang, P.; He, S.; Huang, H. Synthesis and characterization of energetic GAP-b-PAEMA block copolymer. Polym. Eng. Sci. 2012, 52, 768-773. 
[28] Eroglu, M. S.; Hazer, B.; Guven, O. Synthesis and characterization of hydroxyl terminated poly (butadiene)g-poly (glycidyl azide) copolymer as a new energetic propellant binder. Polym. Bull. 1996, 36, 695-701.

[29] Al-Kaabi, K.; Van Reenen, A. J. Synthesis of poly (methyl methacrylate -g-glycidyl azide) graft copolymers using N, N-dithiocarbamate-mediated iniferters. J. Appl. Polym. Sci. 2009, 114, 398-403.

[30] Jin, B.; Shen, J.; Gou, X.; Peng, R.; Chu, S.; Dong, H. Synthesis, Characterization, thermal stability and sensitivity properties of new energetic polymers-PVTNP-g-GAPs crosslinked polymers. Polymers 2016, 8 , 10. doi: $10.3390 /$ polym 8010010

[31] Zhao, B.; Zhang, T.; Ge, Z.; Luo, Y. Fabrication and thermal decomposition of glycidyl azide polymer modified nitrocellulose double base propellants. Sci. China Chem. 2016, 59, 472-477.

[32] Hu, C.; Guo, X.; Jing, Y.; Chen, J.; Zhang, C.; Huang, J. Structure and mechanical properties of crosslinked glycidyl azide polymers via click chemistry as potential binder of solid propellant. J. Appl. Polym. Sci. 2014, 131,40636 .

[33] Hagen, T. H.; Jensen, T. L.; Unneberg, E.; Stenstrøm, Y. H.; Kristensen, T. E. Curing of glycidyl azide polymer (GAP) diol using isocyanate, isocyanate-free, synchronous dual, and sequential dual curing systems. Propell. Explos. Pyrotech. 2015, 40, 275-284.

[34] Min, B. S.; Park, Y. C.; Yoo, J. C. A study on the triazole crosslinked polymeric binder based on glycidyl azide polymer and dipolarophile curing agents. Propell. Explos. Pyrotech. 2012, 37, 59-68.

[35] Landsem, E.; Jensen, T. L.; Kristensen, T. E.; Hansen, F. K.; Benneche, T.; Unneberg, E. Isocyanate-free and dual curing of smokeless composite rocket propellants. Propell. Explos. Pyrotech. 2013, 38, 75-86.

[36] Reshmi, S. K.; Vijayalakshmi, K.; Thomas, D.; Arunan, E.; Reghunadhan Nair, C. Glycidyl azide polymer crosslinked through triazoles by click chemistry: curing, mechanical and thermal properties. Propell. Explos. Pyrotech. 2013, 38, 525-532.

[37] Ding, Y.; Hu, C.; Guo, X.; Che, Y.; Huang, J. Structure and mechanical properties of novel composites based on glycidyl azide polymer and propargyl-terminated polybutadiene as potential binder of solid propellant. $J$. Appl. Polym. Sci. 2014, 7, 40007.

[38] Dubois, C.; Désilets, S.; Nadeau, G.; Gagnon, N. Chemical kinetics and heat transfer issues for a safe bench scale production of partially triazole substituted glycidyl azide polymer (GAP). Propell, Explos, Pyrotech . 2003, 28, 107-113.

[39] Eroglu, M.; Guven, O. Thermal decomposition of poly (glycidyl azide) as studied by high-temperature FTIR and thermogravimetry. J. Appl. Polym. Sci. 1996, 61, 201-206.

[40] Haas, Y.; Eliahu, Y. B.; Welner, S., Infrared laser-induced decomposition of GAP. Combust. Flame. 1994, 96, (3), 212-220.

[41] Sahu, S.; Panda, S.; Sadafule, D.; Kumbhar, C.; Kulkarni, S.; Thakur, J. Thermal and photodegradation of glycidyl azide polymers. Polym. Degrad. Stab. 1998, 62, 495-500.

[42] Fazlığlu, H.; Hacaloğlu, J. Thermal decomposition of glycidyl azide polymer by direct insertion probe mass spectrometry. J. Anal. Appl. Pyrolysis 2002, 63, 327-338.

[43] Korobeinichev, O.; Kuibida, L.; Volkov, E.; Shmakov, A. Mass spectrometric study of combustion and thermal decomposition of GAP. Combust. Flame 2002, 129, 136-150.

[44] Kumar, A.; Lee, Y.-P.; Chen, D.-M. Photodissociation of glycidyl azide polymer with a Nd: YAG laser at $1.064 \mu \mathrm{m}$. Combust. Flame. 2001, 126, 1736-1745.

[45] Tang, C.-J.; Lee, Y.; Litzinger, T. A. Simultaneous temperature and species measurements of the glycidyl azide polymer (GAP) propellant during laser-induced decomposition. Combust. Flame. 1999, 117, 244-256.

[46] Feng, H.; Mintz, K.; Augsten, R.; Jones, D. Thermal analysis of branched GAP. Thermochim. Acta. 1998, 311, 105-111.

[47] Eroglu, M. S.; Guven, O. Characterization of network structure of poly (glycidyl azide) elastomers by swelling, solubility and mechanical measurements. Polymer, 1998, 39, 1173-1176.

[48] Eroglu, M. S.; Baysal, B. M.; Guven, O. Determination of solubility parameters of poly (epichlorohydrin) and poly (glycidyl azide) networks. Polymer, 1997, 38, 1945-1947.

[49] Dogan, M.; Eroglu, M. S.; Erbil, H. Y. Surface free-energy analysis of energetic poly (glycidyl azide) networks prepared by different reactive systems. J. Appl. Polym. Sci. 1999, 74, 2848-2855

[50] Eroglu, M. S. Thermoanalytical life time testing of energetic poly (glycidyl azide) and its precursor, poly (epichlorodydrin). Polym. Bull. 1998, 41, 69-76.

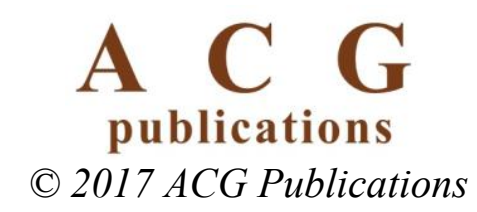

